\title{
The Intervention Research of English Phonics Learning among Chinese School-age Children
}

\author{
Huanhuan $\operatorname{Ren}^{1, \mathrm{a}^{*}}$ and Chi Ma ${ }^{2, \mathrm{~b}}$ \\ 1 Teaching and Research Institute of Foreign Languages, Bohai University, Jinzhou 121013, China \\ 2 Jinzhou Institute of Forestry Research, Jinzhou Forestry Bureau, Jinzhou 121013, China \\ arenhuanhuan2014@163.com, bmachi2014@tom.com
}

\section{Keywords: English Phonics; Intervention Research; Chinese School-age Children}

\begin{abstract}
Learning about phonics is a crucial aspect of learning to read and write, and English phonic learning is gaining traction in recent years in non-English-speaking countries. It's suggested that phonic instruction among Chinese school-age children should be considered and conducted from horizontal intervention of English phonics learning and vertical intervention of English phonics learning. Specifically, the horizontal intervention of English phonics learning among Chinese school-age children could be carried out in two aspects, namely, evaluation of different phonics resources and techniques of utilizing phonics materials, while the vertical intervention of English phonics learning among Chinese school-age children are supposed to be implemented in several areas of learning, including the best start to learn phonics, rudiments of vowel pairs and r-controlled vowels, foundations of consonant blends and consonant digraphs, phonic blending and decoding focusing on letter sounds and efforts for autonomous reading. It's hoped that this research provides a useful reference for future phonics instruction and learning practice among young English language students in China.
\end{abstract}

\section{Introduction}

Phonics is an important part of any reading development program. Students need to learn that there are systematic and predictable relationships between letter combinations and spoken sound. Thus how to conduct phonic instruction among Chinese school-age children? What aspects should be considered by instructors and parents in the process of assisting learners in phonics? Based on the reality analysis of English phonics learning among Chinese school-age children, we attempt to seek for efficient ways and appealing strategies of delivering phonics to Chinese school-age children, in hope of facilitating English language competence and skills of Chinese young learners. This paper is a summary of this research work, which hopefully provides a useful reference for future phonics instruction and learning practice among young language students in China.

\section{The Introduction of English Phonics Learning among Chinese School-age Children}

The Boom of EFL in China. By for now, China is no doubt the country who has the most English speaking population in the whole globe[1], although English is by no means the local medium of communication here (namely English as foreign language (EFL) ). It's easy to find out that English learners boom dramatically in China[2], ranging from beginners who are just starting out to advanced students who want to hone and polish English competence. As English language is learned as EFL by Chinese people, Chinese school-age children try no less hard than people in any other countries. English is taught in China for more than ten years from primary school (from Grade Three) through college. However, it's convinced that the effective English learning process is all along regarded as disputable among Chinese educators since few English learners finally reach a high level of competency after years of industrious learning. Likewise, there is a considerable amount of variation in the roles played by institutes and instructors in the fields of English language education.

The Cognition of Phonics. Phonics is a thorough foundation for reading and writing and it's especially true to EFL learning. Thus what is phonics? It's believed that phonics is a foundational 
literacy skill that focuses on the correspondence between letters (graphemes) and their sounds (phonemes)[3]. There are 40+ sounds in English but only 26 letters that are used to represent these

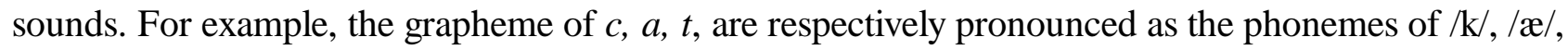
$/ \mathrm{t} /$ in the word cat. Apart from some easy graphemes, there are a lot of rules pertaining to consonant or vowel pairs to be memorized, such as when two different consonants begin or end a word, they usually blend to make a combined sound(e.g. best); when to identical consonants appear side by side, one of them is silent (e.g. mess); when a vowel is followed by the letter $r$, its sound is changed by the $r$ (e.g. card), to name just a few. Through systematical phonics instruction, students learn letter-sound relationships in order to successfully decode (read) and encode (spell) words[4]. It's hoped that children are lead to read and able to read by blending the letter sounds in regular words and even tricky words.

Younger Age Trend for EFL Learning. There is a popular belief that children as language learners are superior to adults[6]. The younger age trend for EFL learning could be supported and underpinned by the theory of children's cognitive development and critical period hypothesis[5]. And there is no doubt that English enlightenment education is gaining traction in recent years in non-English-speaking countries[7]. For reading and writing the children need to be fluent at saying the sounds that go with the letters at the very young age. It has been argued that failing to provide students with explicit and systematic phonics teaching seem to leave important learning up to students to figure out for themselves, which often results in frustration, disengagement and underachievement on the part of the learner[8]. Phonics series especially designed to aid young learners of English in their acquisition of the English language. But the methods and approaches of learning English as a foreign language and native langue do differ greatly[9]. It's suggested that the most effective literacy techniques are used to provide a meaningful start for young children as children learn particularly quickly when there are appealing activities involved.

\section{The Horizontal Intervention of English Phonics Learning among Chinese School-age Children}

Evaluation of Different Phonics Resources. The field of English phonics is replete with a wealth of phonics materials, and the first thing to start a phonics learning is to find out the suitable learning resources for kids. Then what kinds of resources are available to instructors and parents? It's argued that the main channels for English phonics learning among Chinese school-age children are various, including interactive Apps in smart devices, multi ROMs and videos, phonics-focused animated cartoons, series of phonics textbooks, picture books and leveled books, and courses provided by language training schools[10]. It's for sure that the best phonics resources for instructor training and for use with pupils, should be accurate and precise and with quality literacy curriculum and thought-provoking and engaging activities included. Especially, each phoneme in phonics resources must be guaranteed to be recorded by professional native speakers. Instructors and parents should avoid mispronouncing any phoneme in front of kids, not alone let children repeat and reinforce what's wrong. The best part about it is that there are fun chants and songs following each phonics resource to facilitate phoneme acquisition while building on the skills they've learned. Fun and informative activities are offered to engage the learners' interests and help students better achieve their learning goals. Phonics resources are designed to help students retain the new information by incorporating reading, speaking, listening and writing skills. If possible, resources pertaining to phonics are supposed to look beyond the knowledge learned by children and promotes various values for individual learner, such as co-operation, sharing, helping, and appreciating those who help us, etc.

Techniques of Utilizing Phonics Materials. For instructors and parents, the way of making advantage of learning recourses is more important than the recourses themselves, since resources can be found overwhelmingly everywhere and are available to everyone with no big efforts. Initially, it should be decided whether material are utilized at home or in class. The truth is that all the material is suitable for use in school and much of it is also well suited to use at home. But indeed practices of the new sounds and words at home make sense and can not be ignored. Moreover, some of the resources are long-term synthetic courses, featuring a clear grammar-based curriculum alongside parallel syllabi in 
skills and phonics, whereas some of the courses are short-term specialized courses with a strong focus on phonics particularly at the time when summer or winter vacations occur[11]. Parents and instructors should be sure what kind of phonics series is adopted and whether it should be used before or alongside a main course book. Misusing any quality phonics series can lead to inefficiency in English learning. Meanwhile, various learning elements such as interests, levels and styles of English learners, are supposed to be considered when choosing a suitable language training channel for school-age children in China[12]. Instructors and parents should be guided by the pace at which the child wants to go, and tune in with their kids in hope to help reinforce the curriculum's points. Most importantly, positive support from teachers and parents is supposed to be given to school-age children as they benefits from plenty of praise and encouragement whilst learning phonics.

\section{The Vertical Intervention of English Phonics Learning among Chinese School-age Children}

The Best Start to Learn Phonics. Most phonics learning material, if not all of them, get started with the twenty-six alphabets. A variety of lessons are needed to teach and reinforce the alphabets. Efforts in this area can be divided into three parts: letter name, letter formation and letter sounds. Early learners should acquaint themselves with letter names. Singing $A B C$ songs is a good way to help learners do it. Chinese children can just practice letter names through singing along loudly. Then, it's recommended that children learn letter recognition following activities and games for tracing and writing each letter. In the wake of the systematic approach of teaching students how to recognize, trace, and write letters, learners are supposed to be involved in the learning of the sounds of the letters. An enjoyable and interactive way to reinforce single-letter sounds should be included and integrated into learning, whilst learners are completing a variety of exercises. For example, a collection of songs set to popular tunes for each of letter sound, a poster showing the letter sounds, each with a reminder of the action, to name just a few. Children should focus on learning each letter by its sound, not its name, and this will definitely help in blending speech sounds which constitutes a main part of phonics learning.

Rudiment of Vowel Pairs and R-controlled Vowels. Letter recognition and letter sounds do provide the starting point for phonics but it's far from sufficient. All words are made up of sounds, but sounds have more than one way of being written. And it's especially true for vowel learning. Different

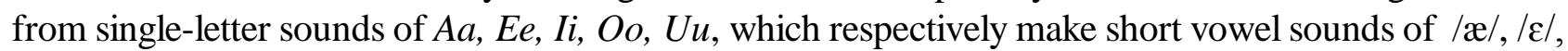
/i/, /o/, / / /, some vowel pairs make long vowel sounds /ei/, /i:/, /ai/, /ov/, /ju/ instead. The long vowel sounds can't be without the involvement of two kinds of vowel pairs: the split vowel pairs and double-letter vowel pairs. Split vowel pairs feature the magic letter $E e$ at the very end of each word, and those words are very common among English words, such as cake, like, home, tune, to name just a few. For double-letter vowel pairs, learners have to get to know a number of vowel blends such as $a y, a i, o a$, $e a$, ee, which can make the long vowel sounds such as in the words of bay, boat, tea, bee, etc. Still, learners should pay special attention to r-controlled vowels, such as ar, ir, er, or, ur. Moreover, these blends make different sounds from non-r-controlled vowels. In the process of teaching, children are encouraged to use body movement, ears, eyes and speech, to help themselves remember vowel pairs and r-controlled vowels. The multi-sensory approach is a very effective way of teaching as well as being fun for the children.

Foundations of Consonant Blends and Consonant Digraphs. Once the children have learnt letter sounds in the initial phase of phonics instruction, they need to be made aware of consonant blends and consonant digraphs. Compared to vowel pairs, consonant pairs are very easy to acquire for school-age children as rudiments of consonant pairs in English language is stable and undergo fewer changes over time. Consonant blends are the result of two or three consonant sounds that are heard when English words are pronounced. For example, in the word flag, the $f l$ portion of the word is a consonant blend. In a blend the two sounds, $f$ and $l$ can each be heard. When sounding out a blend, encourage children to say the two sounds as one unit, so $f l-a-g$ not $f-l-a-g$. This will lead to greater fluency when reading. Apart from consonant pairs, learners have to figure out what consonant digraphs are. It should be made clear to learners that some digraph sounds are represented by two letters, such as 
$s h$. Children should sound out the digraph $s h$, not the individual letters $s-h$. A set of phonics activates and exercises concerning with this part should go with instruction, such as point and repeat, rhyming chant, paint and color, songs and so on. As a child progresses, the learner has the ability to sound out different letter groups once the child has learned the digraphs, initial and final consonant blends.

Phonic Blending and Decoding Focusing on Letter Sounds. With the rudiments of phonics in mind, school-age children are enabled to develop a store of instant words and learn how to use patterns in familiar words to decode and spell hundreds of unfamiliar words. It's suggested that learners begin with simple three-letter words such as cat or hot. A good idea is that rhyming games, poems help tune the ears to the sounds in words. In addition, games like adding a sound, taking away a sound, makes sense. Identifying sounds in words is very fundamental for phonics learning. Besides decoding, learners should move on to working out whole words through blending. Blending is the process of saying the individual sounds in a word and then running them together to make the word. For example, sounding out $d-o-g$ and making $d o g$. Relevant activities introduce the new sounds and puts each sound into the context of a word. However, Chinese school-age learners should pay attention to tricky words in English language. Some words in English have an irregular spelling and cannot be read by blending, such as said, was and the. To make phonics learning more difficult, many of these tricky words are common words. In this regard, the irregular parts of phonics have to be remembered by Chinese school-age children.

Efforts for Autonomous Reading. Instructors and parents embrace phonics in the classroom based on the promise that it can have an positive effect on reading comprehensive abilities of younger learners. In other words, reading is a discount ticket to everywhere and reading is just the main reason why school-age learners try very hard to learn phonics. It makes sense that interesting storybooks are recommended to children who are just ready to read. A kid-appealing book that brings the power of letters directly to early learners. Designed by leading experts in education, storybooks offers children critical reading, phonics and letter recognition skills in fun, easy-to-understand lessons. Controlled vocabulary enables learners to read the words from their letter sound knowledge. Even though there are a few essential tricky words in phonics readers, these words might be shown at the back of book. Besides, full-color, kid-appealing illustrations and exercises help school-age students succeed in reading. It's hoped that phonics readers help Chinese school-age children improve their phonics skills and become independent learners.

\section{Epilogue}

Learning about phonics is a crucial aspect of learning to read and write, and English phonic learning is gaining traction in recent years in non-English-speaking countries. It's suggested that phonic instruction among Chinese school-age children should be considered and conducted from horizontal intervention of English phonics learning and vertical intervention of English phonics learning. Specifically, the horizontal intervention of English phonics learning among Chinese school-age children could be carried out in two aspects, namely, evaluation of different phonics resources and techniques of utilizing phonics materials, while the vertical intervention of English phonics learning among Chinese school-age children are supposed to be implemented in several areas, including the best start to learn phonics, rudiments of vowel pairs and r-controlled vowels, foundations of consonant blends and consonant digraphs, phonic blending and decoding focusing on letter sounds and efforts for autonomous reading. It's hoped that this research provides a useful reference for future phonics instruction and learning practice among young English language students in China.

\section{Acknowledgements}

This work is part of the project of On Intrinsic Logics, Main Implications and Intervetnion Reserach of English Phonics Enlightenment among Chinese School-age Children. This research was supported by the fund of Liaoning Planning of Philosophy and Social Science (Project No. L17CYY005). 


\section{References}

[1][2] J. Walker. The world's English mania. TED. 2009. Retrieved from the information on https://www.ted.com/talks/jay_walker_on_the_world_s_english_mania

[3][4] Phonics. Information on https://www.spellingcity.com/phonics.html

[5][8] H.H. Ren, C. Ma. Study on the practice of phonics in English vocabulary teaching for primary school students. In J. Wang, N. Xin and H. Y. Zhou (eds.). Advances in Computer Science Research v 59. Paris: Atlantis Press. December 2016, pp.1095-1099.

[6] C. Zhang. A Study on the Application of Phonics in English Tutoring in Primary Schools, Hunan Normal University, 2013.

[7] H.H. Ren, C. Ma. The strategies in fostering English enlightenment Education for pre-school children in kindergarten. In J. Wang, N. Xin and H. Y. Zhou (eds.). Advances in Computer Science Research v 59. Paris: Atlantis Press. December 2016, pp.55-59.

[9] C. Fernandez. Of English Teachers Then and Now. The Star, November 11, 2012

[10][11][12] H.H. Ren, C. Ma. The Main Channels of English Phonics Learning among Chinese School-age Children. In W. Jing, X Ning, and Z. Huiyu (eds.). Advances in Social Science, Education and Humanities Research V238. Paris: Atlantis Press. June 2017, pp. 274-278. 